\title{
Cardiac arrest registries: the need for a clear and strategic plan and concept
}

\author{
Jan-Thorsten Gräsner ${ }^{1,2}$, Ingvild Tjelmeland ${ }^{1,3}$, Jan Wnent ${ }^{1,2,4}$ \\ 1 Institute for Emergency Medicine, University Hospital Schleswig-Holstein, Kiel, Germany \\ 2 Department of Anaesthesiology, Campus Kiel, University Hospital Schleswig-Holstein, Kiel, Germany \\ 3 Division of Prehospital Services, Oslo University Hospital, Oslo, Norway \\ 4 School of Medicine, University of Namibia, Windhoek, Namibia
}

RELATED ARTICLE

by Sielski et al, see p. 412

Correspondence to: Prof.Jan -Thorsten Gräsner, MD, FERC, Institute for Emergency Medicine, University Hospital Schleswig-Holstein, Arnold-Heller-Straße 3/808, 24105 Kiel, Germany, phone: +4943150031500, email: jan-thorsten.graesner@uksh.de Received: May 17, 2020. Accepted: May 18, 2020. Published online: May 25, 2020. Kardiol Pol. 2020; 78 (5): 379-380 doi:10.33963/KP.15380 Copyright by the Author(s), 2020
It is well-known and often emphasized in the literature that cardiac arrest is one of the leading causes of death in Europe and high-income countries. By and large, any paper dealing with cardiac arrest starts with an introduction like this. Randomized controlled trials are rare in this patient group due to the nature of the diseases. Due to lack of evidence, additional, knowledge-generating sources should be used. It is also common knowledge that factors like, among others, age, medical history, and acute myocardial infarction have a huge impact on patient outcomes, independently of initial treatment. To gain more information about response, treatment, and outcome after out-of-hospital cardiac arrest (OHCA) and resuscitation, registries started to be regarded as a more relevant and reliable source of information, which helps to acquire evidence on treatment and outcomes in patients after OHCA. All over the world, cardiac arrest registries have been implemented during the last 20 years. However, many European countries still do not lead national registries. The use of registry data to generate additional knowledge has some limitations but also many advantages. One important part of registry work is that the gathered information must be transferred back to the people who delivered the data. This feedback will help to provide an accurate database and suggestions for improvement at the local, regional, and national levels.

Certain factors must be taken into account to successfully establish a registry. First, a resuscitation registry should include data of all patients who sustained cardiac arrest and not only of those who were resuscitated and those who suffered from OHCA due to medical causes.
As described in both large European registry studies, EuReCa (European Registry of Cardiac Arrest) ONE and EuReCa TWO, 1,2 the percentage of cardiopulmonary resuscitations started in patients with OHCA varies among the European countries. Inclusion or exclusion bias will be relevant for analyses and interpretation of the data.

Second, a cardiac arrest registry, regardless of the number of included patients or size of analyzed areas, should focus on cardiac arrest and resuscitation. Additional information in the registry should only be collected if the system is capable of capturing all patients with cardiac arrest.

Third, inclusion of data points should follow the latest Utstein recommendations. ${ }^{3}$ Adopting international standards for documentation, one can compare data not only within a registry, a region, or a country but also within an international community of researchers and clinicians. Therefore, even the registry workers can draw stronger evidence from the respective databases as well as gain knowledge about different emergency medical and healthcare systems.

In Europe, registries, like the one operated in Sweden, have a long history and have been collecting data for more than 20 years. ${ }^{4}$ In some countries, like Norway, OHCA registries are supported by governments or national law. ${ }^{5}$ Some registries cover the whole country, whereas others, like the German Resuscitation Registry, ${ }^{6}$ cover sections of the country or gather local data, like the registry of Amsterdam and North Holland. Worldwide, representatives from Europe, Asia, United States, and Australia/New Zealand collaborate with each other. Within this collaboration, experts from all over the world discuss inclusion criteria, definitions, and descriptions. This knowledge is available for 
all upcoming registries, and collaborators happily share their experience and expertise. Apart from that, more countries have discovered the opportunities provided by a resuscitation registry and are setting up new registries.

Sielski et $\mathrm{al}^{7}$ collected data on OHCA in combination with ACS in a small region in Poland. They used different statistical methods to figure out clinical and procedural risk factors. They have added another puzzle piece to the group of OHCA registries in Poland, Europe, and in the world. They focused on the biggest group of patients with cardiac arrest and followed patients' pathway through the first step of in-hospital treatment.

As already mentioned, registries are one of the big players in the scientific work dealing with OHCA and cardiopulmonary resuscitation. Nevertheless, registries as such will not save more lives. This will be done by medical workers like paramedics, emergency physicians, and the hospital staff. Registries should be used to gain a better understanding and knowledge about patients with cardiac arrest and treatment in order to improve survival.

\section{ARTICLE INFORMATION}

DISCLAIMER The opinions expressed by the author are not necessarily those of the journal editors, Polish Cardiac Society, or publisher.

CONFLICT OF INTEREST All authors are members of the EuReCa steering committee and the study management team of EuReCa ONE and EuReCa TWO. JTG and JW are members of the organization committee of the German Resuscitation Registry, and IT is a member of the organization committee of the Norwegian Resuscitation Registry.

OPEN ACCESS This is an Open Access article distributed under the terms of the Creative Commons Attribution-NonCommercial-NoDerivatives $4.0 \mathrm{In}$ ternational License (CC BY-NC-ND 4.0), allowing third parties to download articles and share them with others, provided the original work is properly cited, not changed in any way, distributed under the same license, and used for noncommercial purposes only. For commercial use, please contact the journal office at kardiologiapolska@ptkardio.pl.

HOW TO CITE Gräsner JT, Tjelmeland I, Wnent J. Cardiac arrest registries: the need for a clear and strategic plan and concept. Kardiol Pol. 2020; 78: 379-380. doi:10.33963/KP.15380

\section{REFERENCES}

1 Gräsner JT, Lefering R, Koster RW, et al. EuReCa ONE-27 Nations, ONE Europe, ONE Registry: a prospective one month analysis of out-of-hospital cardiac arrest outcomes in 27 countries in Europe. Resuscitation. 2016; 105: 188-195.

2 Grasner JT, Wnent J, Herlitz J, et al. Survival after out-of-hospital cardiac arrest in Europe - Results of the EuReCa TWO study. Resuscitation. 2020; 148: 218-226.

3 Perkins GD, Jacobs IG, Nadkarni VM, et al. Cardiac arrest and cardiopulmonary resuscitation outcome reports: update of the Utstein resuscitation registry templates for out-of-hospital cardiac arrest: a statement for healthcare professionals from a Task Force of the International Liaison Committee on Resuscitation (American Heart Association, European Resuscitation Council, Australian and New Zealand Council on Resuscitation, Heart and Stroke Foundation of Canada, InterAmerican Heart Foundation, Resuscitation Council of Southern Africa, Resuscitation Council of Asia); and the American Heart Association Emergency Cardiovascular Care Committee and the Council on Cardiopulmonary, Critical Care, Perioperative and Resuscitation. Resuscitation. 2015; 96: 328-340.

4 Herlitz J. Yearly report of 2017 from the Swedish Cardiac Arrest Registry [in Swedish]. https://www.hlr.nu/svenska-hlr-registret/. Published 2018. Accessed May 10, 2020.

5 Tjelmeland IBM, Kramer-Johansen J, Nilsen JE, et al. Norwegian Cardiac Registry [in Norwegian]. https://www.kvalitetsregistre.no/registers/norsk-hjertestansregister. Published 2019. Accessed May 10, 2020.

6 Wnent J, Gräsner JT, Seewald S, et al. Yearly report form the German Cardiac Arrest Registry [in German]. Anästhesiologie \& Intensivmedizin. 2019; 60: 1-3.

7 Sielski J, Kaziród-Wolski K, Siudak Z. Out-of-hospital cardiac arrest: data from the National Registry of Invasive Cardiology Procedures (ORPKI) in a long-term survival analysis of patients with acute coronary syndromes in a Polish region. Kardiol Pol. 2020; 78: 412-419. 